\title{
Comparison of Tissue Adhesive Glue with Subcuticular Absorbable Suture for Skin Closure Following Thyroid Surgery A single-blinded randomised controlled trial
}

Aditya Musham, ${ }^{1}$ Evangeline M.K. Samuel, ${ }^{2}$ Ashok K. Sahoo, ${ }^{3}$ "Elamurugan T.P., ${ }^{2}$ Manwar A.S. ${ }^{4}$

ABSTRACT: Objectives: This study aimed to compare the skin closure time, postoperative pain and the scar outcome between tissue adhesive and sub-cuticular sutures in thyroid surgery. Methods: This study was conducted in Jawaharlal Institute of Postgraduate Medical Education and Research (JIPMER), Puducherry, a tertiary care hospital in India from March 2017 to December 2019. Adult patients undergoing thyroid surgery were included while those with previous neck surgery, history of keloids/hypertrophic scars and those undergoing concomitant neck dissections were excluded. Following platysma closure, patients were randomised into two groups (tissue adhesive and subcuticular sutures) using the Serially Numbered Opaque Sealed Envelopes technique. A sample size of 64 in each group was calculated for this prospective, single-blinded and randomised controlled trial. The primary outcome was the skin closure time. The secondary outcomes were postoperative pain at 24 hours and scar scoring at $1^{\text {st }}$ and $3^{\text {rd }}$ postoperative month. Statistical analysis was done using SPSS software. Results: A total sample of 124 patients were included in this study, with 61 patients assigned to the suture group and 63 assigned to the tissue adhesive group. The median skin closure time and postoperative pain was significantly lower in the tissue adhesive group as compared to the suture group $(P<0.01)$. There was no statistically significant difference in scar outcome at the $1^{\text {st }}$ or $3^{\text {rd }}$ months between both groups $(P=0.088$ and 0.137 , respectively). There were no wound-related complications in either group. When a subgroup analysis was conducted, no difference was seen in the scar outcome or wound-related complications in patients with comorbidities. There were no instances of allergic contact dermatitis to the tissue adhesive. Conclusion: The use of tissue adhesive leads to lower operative time and less postoperative pain in thyroid surgeries. The scar outcome is comparable between tissue adhesives and subcuticular sutures.

Keywords: Thyroidectomy; Wound Closure Technique; Tissue Adhesives; Sutures; India.

\section{ADVANCES IN KNOWLEDGE}

There was a decrease in operating time when tissue adhesive was used for skin closure compared to sutures.

There was lower immediate postoperative pain when tissue adhesive was used compared to sutures.

There was no difference in scar outcome or wound complications between tissue adhesive and sutures, irrespective of patients' comorbidities.

There was an increase in cost when tissue adhesives were used.

\section{Application to Patient Care}

During thyroidectomy, tissue adhesive can be an attractive option to use instead of sutures in order to decrease operative time and postoperative pain.

The patient must be counselled that the scar outcome is not likely to improve by using tissue adhesive compared to sutures.

The patient must be made aware of the increase in cost if tissue adhesives are used.

$\mathrm{T}$ HYROID DISEASES ARE MORE COMMON IN women and in younger age groups, which makes them the main population group to undergo thyroid surgeries. ${ }^{1}$ Conventional thyroid surgeries are done via a collar-neck incision, which is in the anterior aspect. Such incisions have the potential to leave a conspicuous scar if skin closure was not optimal. Advances such as minimally invasive thyroidectomies were designed in order to achieve a better cosmesis. ${ }^{2}$ However, these surgeries require sophisticated surgical equipment and expertise., ${ }^{3,4}$ Hence, conventional thyroid surgery is still the standard procedure in most patients.

The ideal method of skin closure is a rapid, easyto-apply technique with a good cosmetic outcome. Initially, simple sutures were used, but they were found to have a poor scar outcome due to railroad tracking. ${ }^{6}$ Subsequently, subcuticular sutures were used, which showed a better scar outcome with less post-procedure pain. ${ }^{6}$ However, these require meticulous work, time 
to gain expertise and have the risk of needlestick injuries. $^{7-9}$

Tissue adhesive glue was introduced as an ideal system of wound closure. ${ }^{10}$ It is composed of monomeric cyanoacrylate which polymerises on contact with moisture to form an adhesive layer over the skin..$^{10}$ It is an attractive choice for thyroidectomies as it is easy to apply and less time-consuming. ${ }^{8}$ Its main disadvantage is contact dermatitis, which has been purported to vary with climate. ${ }^{11,12}$ This is because the antigen-presenting cells identify the monomeric form of cyanoacrylate. In arid climates, it takes time for polymerisation, thereby increasing the chance of a reaction. ${ }^{12}$

Studies have been performed, comparing subcuticular sutures to tissue adhesives in but differences in postoperative pain, wound dehiscence rates and operative time have not been clearly elucidated. ${ }^{13,17,19-22}$ The present study aimed to examine the effects of both methods of repair on postthyroidectomy patients in a South Asian country with equatorial climate as well as a wide variation in the skin type of its population.

\section{Methods}

The study was designed as a prospective, singleblinded and randomised controlled trial. It was conducted from March 2017 to December 2019 in the Department of General Surgery in Jawaharlal Institute of Postgraduate Medical Education and Research (JIPMER), Puducherry, a tertiary care hospital in India.

The sample size was calculated based on a similar study conducted by Consorti et al. ${ }^{13}$ Using OpenEpi software, a sample size of 64 in both groupssubcuticular suture group and tissue adhesive groupwas calculated after taking into account the difference in time required for skin closure as the primary criterion, with level of significance as $5 \%$ and the power of study set to $90 \%$, expecting a dropout rate of $10 \%$. All patients between 18-80 years of age undergoing thyroid surgery during the study period were included. Patients with previous neck surgery, history of keloids or hypertrophic scars and those undergoing concomitant neck dissections were excluded.

All patients received an intravenous dose of prophylactic antibiotic (Inj. Cloxacillin 500 mg) within 30 minutes from the time of skin incision, as per the departmental policy at the researchers' centre. The surgery was done as per the standard operating procedure. Once the resection was done, a 14. F closed-suction drain was placed in all patients, which is part of the operative policy at the centre. The strap muscles and platysma were approximated using
2-0 and 3-0 round-bodied vicryl simple sutures, respectively. Following platysma closure, the patients were randomised into two groups. Tissue adhesive (octyl 2-cyanoacrylate; Dermabond ${ }^{\oplus}$, Ethicon Inc, New Jersey, USA) was used in the study while 3-0 sized monocryl suture (Lotus Surgicals Pvt Limited, Uttarakhand, India) was used for subcuticular suturing. For each patient, one unit was used according to the group allotted.

Postoperative analgesia was standardised in both groups, with all patients receiving intravenous tramadol and ketorolac alternately every four hours for the first 24 hours in the postoperative period. Scar assessment was done at the $1^{\text {st }}$ and $3^{\text {rd }}$ postoperative months.

Randomisation was done using computergenerated random numbers and allocation was done using the Serially Numbered Opaque Sealed Envelopes technique, which were opened after platysma closure.

The primary outcome measured was the skin closure time (in minutes). In the tissue adhesive group (Group A), after closing the platysma, the skin closure start time was noted once the skin edges were dry. The tissue adhesive was applied slowly in two layers, using a brushing motion. A gap of 15 seconds was given between the applications and the adhesive was allowed to set for 60 seconds, at which point the skin closure end time was noted. A dressing was not applied.

In the subcuticular suture group (Group B), after closing the platysma, the skin closure start time was noted. The skin was closed by subcuticular absorbable suture and dressing was applied. Once done, the skin closure end time was noted.

The secondary outcomes measured were postoperative pain at 24 hours and scar scoring at the $1^{\text {st }}$ and $3^{\text {rd }}$ postoperative months. Postoperative pain was assessed using a 10-point Visual Analog Scale. ${ }^{14}$ The scar cosmesis was assessed using the Manchester Scar Scale by a researcher who was blinded regarding the method of skin closure. ${ }^{15}$ The cost per unit used was also compared between the two groups.

Statistical analysis was done using the Statistical Package for the Social Sciences (SPSS) software, version 19.0 (IBM Corporation, Armonk, New York, USA). Continuous variables were expressed as mean or median based on the distribution. Ordinal variables were expressed as median. Categorical variables were expressed as proportions, frequencies or percentages. Continuous variables were compared using unpaired t-test. Ordinal variables were tested using Pearson Chi-squared test. The difference of medians of skin closure time, pain and scar scores at the $1^{\text {st }}$ and $3^{\text {rd }}$ postoperative months between both groups was tested using Mann-Whitney U test. 


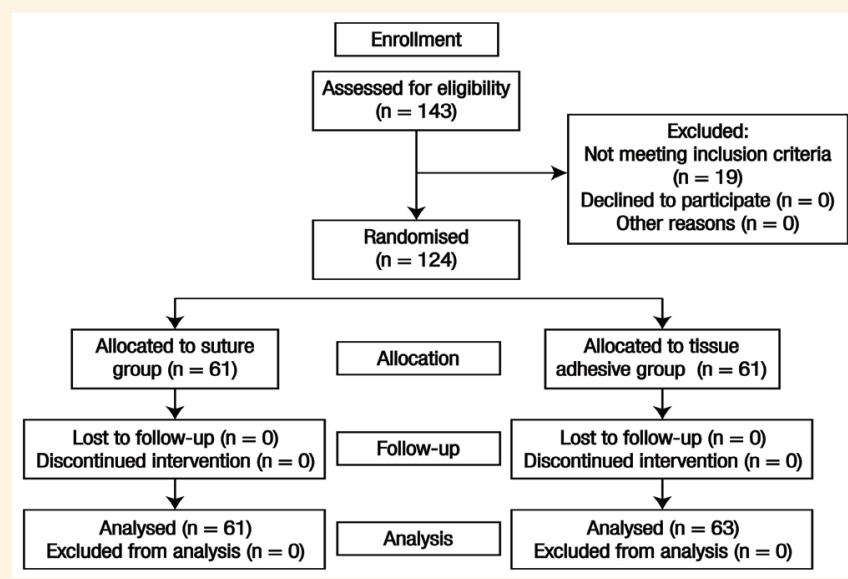

Figure 1: CONSORT 2010 flow diagram of patient recruitment for this study $(\mathrm{N}=124)$.

Table 1: Demographic and clinical parameters of patients in the two groups of this study $(\mathrm{N}=124)$

\begin{tabular}{|c|c|c|c|}
\hline \multirow[t]{2}{*}{ Parameter } & \multicolumn{2}{|c|}{ n (\%) } & \multirow{2}{*}{$\begin{array}{c}P \\
\text { value }\end{array}$} \\
\hline & $\begin{array}{l}\text { Subcuticular } \\
\text { suture } \\
(\mathbf{n}=6 \mathbf{6 1})\end{array}$ & $\begin{array}{c}\text { Tissue } \\
\text { adhesive } \\
(n=63)\end{array}$ & \\
\hline $\begin{array}{l}\text { Mean age } \pm S D \\
\text { in years }\end{array}$ & $42.62 \pm 12.28$ & $42.03 \pm 11.80$ & 0.785 \\
\hline \multicolumn{4}{|l|}{ Gender } \\
\hline Male & $17(27.87)$ & $11(17.46)$ & \multirow{2}{*}{0.166} \\
\hline Female & $44 .(72.13)$ & $52(82.54)$ & \\
\hline \multicolumn{4}{|c|}{ Preoperative diagnosis } \\
\hline Benign & $44(72.13)$ & $46(73.02)$ & \multirow{2}{*}{0.912} \\
\hline Malignant & $17(27.86)$ & 17 (26.98) & \\
\hline \multicolumn{4}{|l|}{ Type of surgery } \\
\hline $\begin{array}{l}\text { Hemithyroid- } \\
\text { ectomy }\end{array}$ & $29(47.54)$ & $30(47.62)$ & \\
\hline $\begin{array}{l}\text { Subtotal } \\
\text { and total } \\
\text { thyroidectomy }\end{array}$ & $32(52.46)$ & $33(52.38)$ & 0.993 \\
\hline
\end{tabular}

Table 2: Comparison of skin closure time in the two groups of this study

$\begin{array}{lcc}\text { Group } & \begin{array}{c}\text { Median in } \\ \text { seconds } \\ \text { (min-max) }\end{array} & \text { P value* } \\ \text { Suture } & 390(130-750) & \\ \text { Tissue adhesive } & 250(90-720) & <0.01^{+} \\ \text {"Mann-Whitney U test. } & \\ & \\ & \text { Statistically significant with 1\% level of significance. }\end{array}$

Approval was obtained from Institute Ethics Committee at the Jawaharlal Institute of Postgraduate Medical Education and Research (JIPMER),
Table 3: Comparison of postoperative pain score between the two groups of this study

$\begin{array}{lcc}\text { Group } & \begin{array}{c}\text { Median } \\ \text { (min-max) }\end{array} & \text { P value* } \\ \text { Suture } & 6(1-9) & <0.01^{+} \\ \text {Tissue adhesive } & 5(1-9) & \\ \text { "Mann-Whitney U test. } & \\ \text { 'Statistically significant with 1\% level of significance. } & \end{array}$

Table 4: Comparison of scar score in the $1^{\text {st }}$ and the $3^{\text {rd }}$ postoperative month between the two groups of this study

$\begin{array}{lcc}\text { Group } & \begin{array}{c}\text { Median } \\ (\mathbf{m i n}-\mathbf{m a x})\end{array} & \boldsymbol{P} \text { value* } \\ \begin{array}{l}\mathbf{1}^{\text {st }} \text { postoperative month } \\ \text { Suture }\end{array} & 10(6-15) & \\ \text { Tissue adhesive } & 9(5-15) & 0.088 \\ 3^{\text {rd }} \text { postoperative month } & \\ \text { Suture } & 8(6-13) & \\ \text { Tissue adhesive } & 8(5-13) & 0.137 \\ \text { "Mann-Whitney U test. } & \end{array}$

Puducherry (JIP/IEC/2017/0213), registered in CTRI (CTRI/2018/02/011698). Written informed consent was obtained from the participants.

\section{Results}

Among the 143 patients who underwent thyroid surgery during this study period, 124 patients were included in the study based on the inclusion criteria. The schematic representation of the study as per the CONSORT 2010 (Consolidated Standards of Reporting Trials) flow diagram is shown in Figure 1. The baseline characteristics were comparable between the two groups [Table 1]. 
The mean age of patients in the suture group was $42.62 \pm 12.28$ years and of tissue adhesive group was $42.03 \pm 11.80$ years. The majority of the study participants were female, both in the suture group and in the tissue adhesive group $(72.13 \%$ and $82.53 \%$, respectively). The preoperative diagnosis distribution and type of surgery done in both the groups were similar.

The median skin closure time in suture group and the adhesive group was 390 and 250 seconds, respectively, which was a statistically significant difference $(P<0.01)$ [Table 2].

The median pain score between the two groups also showed significant difference $(P<0.01)$ [Table 3]. However, there was no statistically significant difference in scar outcome at the $1^{\text {st }}$ and $3^{\text {rd }}$ months between both the groups $(P=0.088$ and 0.137 , respectively) [Tables 4]. There were no wound-related complications in either group. The cost of one unit of tissue adhesive was found to be 2,000 Indian Rupees (INR; approximately 24 US dollars) and one unit of suture was 899 INR (approximately 11 US dollars).

\section{Discussion}

The use of tissue adhesives has gained significance in recent days owing to the concept of no-suture cosmetic surgery. Previously, subcuticular suturing was a standard technique used for skin closure, especially in areas of cosmetic interest. Studies comparing traditional methods of closure and tissue adhesive are few in number with contradicting results. ${ }^{13,17,19-22}$ Therefore, the researchers conducted this study to add to the body of existing knowledge.

The present study showed that there was a significant difference in skin closure time between the tissue adhesive group and suture group. Tissue adhesive reduced skin closure time by $36 \%$ to that of subcuticular suture. Saving theatre time is essential to avoid wastage of hospital resources and to avoid dissatisfaction of staff, which would affect the quality of work. ${ }^{16}$ Other studies also came to the same conclusion as this study. ${ }^{13,17}$

Postoperative pain between the two groups has been analysed in the present study, which showed a significant difference on the first postoperative day between the suture and tissue adhesive group, which is a novel finding. In the available literature, there is no clear evidence that postoperative pain was affected by using tissue adhesive, compared to sutures. In a randomised cohort study by Chamariya et al., it was found that using a tissue adhesive causes less pain after closure of the episiotomy wound compared to suturing. ${ }^{18}$ However, the skin closure technique was mattress suturing and the area of interest was the perineum. With respect to thyroid surgeries, Pronio et al. mentioned that $26.3 \%$ of patients in the staple group and $9.3 \%$ of the tissue adhesive group had pain, which was not a significant difference; however, they compared between staples and tissue adhesives and the severity of pain was not measured. ${ }^{20}$ Amin et al. compared pain at the $1^{\text {st }}$ and $10^{\text {th }}$ postoperative day using the visual analogue scale and concluded that there was no difference between staples and tissue adhesives $(P=0.829$ and 0.931 , respectively $){ }^{21}$ The findings of the present study can be explained by the fact that there was a lower amount of tissue handling and dissection, no needle pricks and no suture lying within the skin postoperatively in the tissue adhesive group.

Scar outcome was another important factor for assessing a skin closure technique. Consorti et al. have assessed scar outcome at six weeks using Patient and Observer Scar Assessment Scale score. ${ }^{13}$ Based on observer assessment, subcuticular suture was favoured above tissue adhesive, but there was no difference on the patients' assessment. This study was, however, criticised for assessing scars at six weeks as it may be too early to assess scar outcome with most surgical scars taking an optimal time of three months to mature. Ciufelli et al. concluded that there was better scar outcomes in the tissue adhesive group than suture group on the $10^{\text {th }}$ day; however, at three months, there was no difference. ${ }^{19}$ Several other studies also showed that there was no significant difference in the scar outcome at the $3^{\text {rd }}$ month between both the groups. ${ }^{20-22}$ The researchers found concordant results in the present study with there being no difference in the scar outcome both at the $1^{\text {st }}$ and $3^{\text {rd }}$ months between the groups.

In the review by Dumville et al., it was stated that sutures were significantly better than tissue adhesives for minimising dehiscence, but the available evidence was of a low quality. ${ }^{9}$ A need to study a subset of the population that have comorbidities that influence the rates of wound breakdown was also noted. In the present study, the researchers have tried to bridge this gap in knowledge by taking comorbidities into account with $16.39 \%$ of patients in suture group and $15.87 \%$ in the tissue adhesive group having comorbidities. It was seen on a subgroup analysis that there was no difference in the scar outcome or wound-related complications in these patients. However, the validity of this statement was questionable due to the small subgroup size (15-16\%). Such a statement requires larger studies to reinforce this conclusion. 
The time for closure of the skin incision would depend on the skin incision length which depends on the extent of surgery. Some studies did not differentiate between the different types of thyroid surgeries. ${ }^{19,20}$ Consorti et al. had only taken patients undergoing total thyroidectomy patients, whereas Bozkurt and Saydam had taken all head and neck surgeries into account. ${ }^{13,17}$ In the present study, the researchers have taken patients undergoing different extents of thyroid surgeries and randomised them into both groups. The patients were equally distributed into either arm [Table 1]. The present study shows that hemithyroidectomy took significantly less time in both groups, which may be attributed to the incision length. As all types of thyroid surgeries were included in the present study, this was prevented from being a confounding factor.

In the present study, each patient required one package of 3-0 monocryl suture which costs 899 INR (approximately 11 US dollars) or one vial of tissue adhesive which costs 2,000 INR (approximately 24 US dollars). This showed that the tissue adhesive was twice as expensive as a suture. However, there was no need of dressing or follow-up visits for suture removal in tissue adhesive. Hence, the overall cost involved in both groups was difficult to estimate and compare. Bozkurt and Saydam also had similar results in their study. ${ }^{17}$

The disadvantages of cyanoacrylate were mainly technical and care should be taken to prevent them. In the literature, it was reported that the adhesive can seep into the edges of the wound, impairing wound healing and affecting the scar cosmesis by causing a foreign body reaction..$^{23}$ Asai et al. reported that $1.6 \%$ of patients had developed allergic contact dermatitis after the first application of cyanoacrylate tissue adhesive. ${ }^{11}$ Bitterman and Sandhu reported a papulovesicular rash at the application site two weeks postoperatively showing residual glue found at the incision site, which improved once the glue was washed off. ${ }^{12}$ None of these effects were noted in any of the patients of the present study.

Another advantage of tissue adhesive is its antimicrobial nature. Cyanacrylate, in the unused form, is manufactured in the monomeric state. When it encounters moisture, it polymerises, forming a layer of waterproof material, which forms a physical barrier to the entry of microbes, obviating the need for dressing. It can also inhibit microbial growth in vitro. This is thought to be due to high electronegative charge on the cyanoacrylate monomer which reacts with the positively charged polysaccharide capsule of organisms. ${ }^{24}$

The present study was not without limitations of its own. Firstly, it was a single institutional study.
The skin closure was not done by a single surgeon in all patients. Thus, the experience of the surgeon with the technique may have affected the results, especially skin closure time and scar outcome. The length of the skin incision was not measured, which can affect the skin closure time. Scar outcome was assessed by a blinded observer using Manchester Scar Score, which is subjective. Patient satisfaction and their assessment of the scar were not evaluated. The patient's preference may also affect the choice of skin closure.

\section{Conclusion}

Tissue adhesive is faster to apply than subcuticular sutures in all types of thyroid surgeries. They also result in less immediate postoperative pain and with a comparable scar cosmesis. There was no difference seen in the wound-related complications between the two groups, even among patients with comorbidities. However, the cost involved in tissue adhesives is significantly higher compared to sutures. Hence, it is proposed that the use of tissue adhesives can replace subcuticular sutures in thyroid skin closure, if the patient is able to afford it.

\section{AUTHORS' CONTRIBUTION}

AM was involved in the formulation of the protocol and its execution. EMKS was involved in the data collection and the drafting of the manuscript. AKS was involved in protocol creation. ETP, MAS and AKS edited of the manuscript. All authors approved the final version of the manuscript.

\section{CONFLICT OF INTEREST}

The authors declare no conflicts of interest.

\section{FUNDING}

No funding was received for this study.

\section{References}

1. Taylor PN, Albrecht D, Scholz A, Gutierrez-Buey G, Lazarus JH, Dayan CM, et al. Global epidemiology of hyperthyroidism and hypothyroidism. Nat Rev Endocrinol 2018; 14:301-16. https://doi.org/10.1038/nrendo.2018.18.

2. Ohgami M, Ishii S, Arisawa Y, Ohmori T, Noga K, Furukawa T, et al. Scarless Endoscopic Thyroidectomy: Breast approach for better cosmesis. Surg Laparosc Endosc Percutan Tech 2000; $10: 1-4$.

3. Lang BH-H, Wong K-P. A comparison of surgical morbidity and scar appearance between gasless, transaxillary endoscopic thyroidectomy (GTET) and minimally invasive video-assisted thyroidectomy (VAT). Ann Surg Oncol 2013; 20:646-52. https://doi.org/10.1245/s10434-012-2613-y. 
4. Stalberg P, Delbridge L, van Heerden J, Barraclough B. Minimally invasive parathyroidectomy and thyroidectomy-current concepts. Surgeon 2007; 5:301-8. https://doi. org/10.1016/s1479-666x(07)80029-1.

5. Lombardi CP, Bracaglia R, Revelli L, Insalaco C, Pennestrì $\mathrm{F}$, Bellantone $\mathrm{R}$, et al. [Aesthetic result of thyroidectomy: evaluation of different kinds of skin suture]. Ann Ital Chir 2011; 82:449-55.

6. Swanson NA, Tromovitch TA. Suture materials, 1980s: Properties, uses, and abuses. Int J Dermatol 1982; 21:373-8. https://doi.org/10.1111/j.1365-4362.1982.tb03154.x.

7. Singer AJ, Hollander JE, Valentine SM, Thode HC, Henry MC. Association of training level and short-term cosmetic appearance of repaired lacerations. Acad Emerg Med 1996; 3:378-83. https://doi.org/10.1111/j.1553-2712.1996.tb03454.x.

8. Singer AJ, Quinn JV, Clark RE, Hollander JE, TraumaSeal Study Group. Closure of lacerations and incisions with octylcyanoacrylate: A multicenter randomized controlled trial. Surgery 2002; 131:270-6. https://doi.org/10.1067/ msy.2002.121377.

9. Dumville JC, Coulthard P, Worthington HV, Riley P, Patel N, Darcey J, et al. Tissue adhesives for closure of surgical incisions. Cochrane Database Syst Rev 2014; 28:CD004287. https://doi. org/10.1002/14651858.CD004287.pub4

10. Trott AT. Cyanoacrylate Tissue Adhesives: An Advance in Wound Care. JAMA 1997; 277:1559-60. https://doi. org/10.1001/jama.1997.03540430071037.

11. Asai C, Inomata N, Sato M, Koh N, Goda S, Ishikawa H, et al. Allergic contact dermatitis due to the liquid skin adhesive Dermabond $^{\circledast}$ predominantly occurs after the first exposure. Contact Dermatitis 2021; 84:103-8. https://doi.org/10.1111/ cod. 13700 .

12. Bitterman A, Sandhu K. Allergic contact dermatitis to 2-octyl cyanoacrylate after surgical repair: Humidity as a potential factor. JAAD Case Rep 2017; 3:480-1. https://doi. org/10.1097/00006534-199811000-00022.

13. Consorti F, Mancuso R, Piccolo A, Pretore E, Antonaci A Quality of scar after total thyroidectomy: a single blinded randomized trial comparing octyl-cyanoacrylate and subcuticular absorbable suture. ISRN Surg 2013; 2013:270953. https://doi.org/10.1155/2013/270953.

14. Hayes MHS, Patterson DG. Experimental developement of the graphics rating method. Physiol Bull 1921; 18:98-9.
15. Beausang E, Floyd H, Dunn KW, Orton CI, Ferguson MW. A new quantitative scale for clinical scar assessment. Plast Reconstr Surg 1998; 102:1954-61. https://doi.org/10.1097/00006534199811000-00022.

16. Huskisson EC. Measurement of pain. Lancet 1974; 2:1127-31. https://doi.org/10.1016/s0140-6736(74)90884-8.

17. Bozkurt MK, Saydam L. The use of cyanoacrylates for wound closure in head and neck surgery. Eur Arch Otorhinolaryngol 2008; 265:331-5. https://doi.org/10.1007/s00405-007-0454-2.

18. Chamariya S, Prasad M, Chauhan A. Comparison of dermabond adhesive glue with skin suture for repair of episiotomy. Int J Reprod Contracept Obstet Gynecol 2016; 5:3461-5. https:// doi.org/10.18203/2320-1770.ijrcog20163423.

19. Alicandri-Ciufelli M, Piccinini A, Grammatica A, Molteni G, Spaggiari A, DI Matteo S, et al. Aesthetic comparison between synthetic glue and subcuticular sutures in thyroid and parathyroid surgery: A single-blinded randomised clinical trial. Acta Otorhinolaryngol Ital 2014; 34:406-11.

20. Pronio A, Filippo ADD, Narilli P, Caporillli D, Vestri A, Ciamberlano B, et al. Closure of cutaneous incision after thyroid surgery: A comparison between metal clips and cutaneous octyl-2-cyanoacrylate adhesive. A prospective randomized clinical trial. Eur J Plast Surg 2011; 34:103-10. https://doi. org/10.1007/s00238-010-0477-6.

21. Amin M, Glynn F, Timon C. Randomized trial of tissue adhesive vs staples in thyroidectomy integrating patient satisfaction and Manchester score. Otolaryngol Head Neck Surg 2009; 140:703-8. https://doi.org/10.1016/j.otohns.2009.01.003.

22. Yang Y-L, Xiang Y-Y, Jin L-P, Pan Y-F, Zhou S-M, Zhang X-H, et al. Closure of skin incision after thyroidectomy through a supraclavicular approach: A comparison between tissue adhesive and staples. Scand J Surg 2013; 102:234-40. https:// doi.org/10.1177/1457496913490610

23. Elmasalme FN, Matbouli SA, Zuberi MS. Use of tissue adhesive in the closure of small incisions and lacerations. J Pediatr Surg 1995; 30:837-8. https://doi.org/10.1016/0022-3468(95)90760-

24. Mizrahi B, Weldon C, Kohane D. Tissue Adhesives as Active Implants. In: Zilberman, M, Eds. Active Implants and Scaffolds for Tissue Regeneration. Berlin, Germany: Springer, 2011. pp. 39-56. https://doi.org/10.1007/8415_2010_48. 